\title{
GEREFORMEERDE TEOLOGIESE OPLEIDING EN DIE TOEKOMS
}

\author{
J.J. Kritzinger \\ ISWEN \\ Universiteit van Pretoria \\ PRETORIA
}

\begin{abstract}
In this anicle the author highlights five trends which will increasingty challenge reformed theological training in the South Africa of the future. These trends are illustrased byare:

- the fast-growing church,

- the growing nominality,

- the increasing poverty,

- the growing cities, and

- the growing integration in society.
\end{abstract}

\section{INLEIDEND}

Teologiese opleiding behoort te alle tye kontekstueel te wees. Daarmee word bedoel dat die opleiding op die werklike situasie behoort ingestem te word, want die bediening in die kerk behoort op die werklikheid gerig te wees.

Die probleem is egter dat daar in gereformeerde kringe dikwels in so ' $n$ mate klem op die teologiese begronding van die opleiding van leraars gele word dat die situasie van die kerk in die wereld nie genoegsaam tot sy reg kom nie. Die opleiding word ontwerp en aangebied soos wat die teoloë meen dit moet wees. Alles word oorheers deur die teologiese inhoud. Die kerk moet dan maar genoeê neem met die leraars wat beskikbaar gestel word, of die opleiding geskik is vir die situasie al dan nie.

Die afgelope dekades het een strewe die teologiese opleiding in die gereformeerde jong kerke oorheers: hoër akademiese standaarde. Die toelatingsvereistes is algaande verhoog sodat die ideaal van 'n sesjarige kursus met die verwerwing van twee grade bereik kon word (vgl. Odendaal (1980) vir hierdie verhaal in verband met die NG Kerk se Stofberg Teologiese Skole). Hierdie strewe is op sigself goed, maar nie as dit ten koste van ander ewe belangrike beginsels geskied nie. In watter mate is die werklike behoeftes van die kerk-in-die-wêreld ook in ag geneem, of is dit maar die ideale van die Westerse teologie wat (slaafs) nagevolg is (Van der Walt, 1988:17)? 
Hoe grondig die teologie ook al bestudeer is, ' $n$ wèreldvreemde opleiding sou nie goed kon wees nie. (Vgl. hiervoor ook die opmerkings van Pretorius, 1986:244.)

Vir die doeleindes van hierdie artikel word vyf groeitendense in die kerk en samelewing aan die orde gestel wat vorentoe ongetwyfeld belangrike uitdagings aan teologiese opleiding sal stel en wat nie uit die oog verloor moet word nie. Hulle is (a) die snelle groei in (sommige dele van) die kerk, (b) die groeiende naamchristendom in Suider-Afrika, (c) die toenemende armoede in Suider-Afrika, (d) die verstedelikingsverskynsel, en (e) die groeiende gemeenskaplikheid in die nuwe Suid-Afrika.

\section{DIE GROEIENDE KERK IN SUIDER-AFRIKA}

'n Groot deel van die kerk in Suider-Afrika is nie numeries aan die groei nie. Prominent in hierdie groep is die Afrikaanse gereformeerde Kerke. Met die uitsondering van die charismatiese en Pinksterkerke is daar trouens prakties geen kerkgroep wat in die blanke gemeenskap besondere groei toon nie. Die blanke bevolkingsdeel het, soos ons aimal weet, tans 'n baie lae biologiese groeikoers. Nogtans hou die groei van die gevestigde Kerke nie eers tred met die bevolkingsgroei nie.

In die swart gemeenskap is die saak ietwat anders. Hier het die kerklike affiliasie oor die afgelope dekades konstant vinniger gegroei as die bevolking, veral op die platteland. Tog was dit onder die gevestigde kerke ${ }^{1}$ eintlik slegs die Rooms-Katolieke Kerk en die (Nederduitse) Gereformeerde Kerke ${ }^{2}$ wat enigsins gesonde groei getoon het. Die ander - byvoorbeeld die Anglikane, Kongregasionaliste, Lutherane, Metodiste en Presbiteriane - het relatiewe verliese getoon. In die swart gemeenskap was die groei in die Christengemeenskap hoofsaaklik te danke aan die werwingskrag van die onafhanklike swart Kerke en die Pinkstergroeperings.

In Suider-Afrika het ons dus wel met 'n groeiende kerk te doen, danksy die feit dat die swart Christene reeds meer as twee-derdes (en 'n steeds groter wordende deel) van die Christengemeenskap uitmaak. Hoe ironies dit ookal mag wees, is dit so dat snelle groei ernstige probleme vir 'n Kerk ${ }^{3}$ inhou. By al die blydskap wat daar moet wees oor

' Hierdie term word gebruik vir die ouer kerke wat uit tradisionele sendingaksies gespruit het. Die Engelse term is die main line churches.

${ }^{2}$ Sensussyfers onderskei gewoonlik nie tussen die swart lidmate van die Afrikaanse gereformeerde Kerke nie. In die praktyk maak die lidmate van die NG Kerk in Afrika verreweg die grootste deel hiervan uil. Terwyl die swart Gereformeerdes gesonde groci getoon het in die vorige dekades, is daar aanduidings dat dit nie so goed gegaan bet in die tagtigerjare nie. 
die vinnige groei van die kerk in Swart Afrika, is daar kenners wat met groot kommer beweer dat die kerk in Afrika hom "dood groei" (vgl. veral Hastings (1967) en Kritzinger (1979:2)).

Een sensitiewe terrein in ' $\mathrm{n}$ groeiende kerk is die opleiding en voorsiening van werkkragte. Daar is ten minste $t$ wee redes waarom daar vandag in Suider-Afrika moeilik genoeg leraars aan die snel groeiende swart Kerke gelewer kan word:

- Die finansiële posisie van die gemeentes (en natuurlik die gemeenskap as geheel) is sodanig dat (a) die opleiding en (b) die onderhoud van leraars net te duur vir die gemeente is. Dit is vir die meeste Kerke onmoontlik om die koste verbonde aan die opleiding van groot getalle werkkragte te dra. Gevolglik word te min mense opgelei en in diens gestel. Buitendien is daar min kandidate, want finansiêel gesproke is aan die kerklike diens nie 'n kompeterende salaris verbonde nie. Die kern van die probleem is dat ' $n$ arm gemeenskap die erfgename van 'n duur struktuur (akademies hoogs opgeleide mense met middelklasverwagtinge) geword het (Kritzinger, 1979:26).

- Die hoë akademiese vereistes wat aan kandidate gestel word. Baie min mense voldoen aan die toelatingsvereistes, en hulle wat wel voldoen, kwalifiseer ook vir ander meer aantreklike rigtings. Daar is nie ruimte vir ouer mense, bewese leiers in die opleiding nie (vgl. 1 Tim. 3; 2 Tim. 2 en 4; Tit. 1). Die struktuur is ontwerp vir jong, ongetroude mense - met baie belofte (maar slegs belofte!).

Hierdie probleem is wel deeglik akuut in Suider-Afrika, maar is geensins uniek aan hierdie gebied nie. Gedurende die sestigerjare het die afmetings wat die tekorte aan leraars in Latyns-Amerika aangeneem het, daartoe gelei dat 'n nuwe benadering tot teologiese opleiding tot stand gekom het, wat genoem is Theological Education by Extension (TEE) (vgl. Glasser e.a., 1976:399-457, en ook by Kritzinger, 1979:125). Sedertdien het hierdie belowende model wereldwyd posgevat en reeds 'n groot bydrae gelewer om verligting in soortgelyke kneliende situasies teweeg te bring. Kortliks kom dit daarop neer dat, in plaas daarvan om studente te onttrek (extract) aan hulle gemeenskap en ten duurste op te lei, die opleiding nou uitgebrei (extend) word na die studente toe. Die basiese leerstof word skriftelik voorsien, maar die studente word ook op 'n gereelde basis persoonlik in werkgroepe ontmoet waar die leerstof bespreek en toegepas word. Op hierdie manier word veel groter getalle opgelei; ook werkende

\footnotetext{
${ }^{3}$ Die term gemeente word gebruik vir die plaaslike kerk, Kerk (met boofletter) vir 'n bepaalde kerkverband (denominasie), en kerk (met klein letter) vir die algemene kerk.
} 
mense kan opleiding ontvang; en elkeen kan dit op sy/haar eie vlak van bevatlikheid verwerk.

TEE is nie die enigste moontlike oplossing nie. Die punt is egter dat groeiende kerke in die armer gemeenskappe die teologiese opleiding voor die uitdaging van herstrukturering en modelveranderings stel.

\section{DIE GROEIENDE NAAMCHRISTENDOM IN SUIDER-AFRIKA}

Die nominalisme is een van die oorweldigendste indrukke van die huidige kerklike toneel. Daar is in Suider-Afrika reeds 'n sterk naamchristendom teenwoordig, en daar kan op grond van die tendense elders verwag word dat dit ook hier nog sal toeneem.

Dit is met 'n skok dat 'n mens ontdek watter groot verskil daar is tussen (a) die getalle mense wat hulleself as kerklidmate in die sensusopnames van die staat aangee en die getalle wat in kerklike statistieke verskyn (vgl. Kritzinger, 1988:18); (b) die getalle mense op die boeke van die kerk en hulle wat Sondae op die kerkbanke sit (Van Eeden, 1986:72; Möller, 1974:219); en (c) die getal meelopers en die werklik oortuigde Christene in die gemeentes. Sommige van hierdie getalle is meetbaar en ander nie. Die algemene tendens is egter ongelukkig dat veel minder mense aktief belydende (wedergebore) Christene is as die pragtige $77 \%$ van die bevolking wat in 1980 as Christene aangegee is. Daar kan nie twyfel daaroor wees dat die hoë kerklike affiliasie onder sommige Suider-Afrikaanse groepe (vgl. Kritzinger, 1988:53) 'n ernstige graad van nominaliteit versluier nie.

Die driērlei aard van hierdie naamchristendom

\subsection{Sekulère lewenstyl}

In die eerste plek is die sekulêre lewenstyl, tiperend van die Westerse beskawing, by 'n groot deel van die bevolking deurslaggewend. Die verskillende gesigte van hierdie lewenswyse is materialisme, praktiese godsdiensloosheid, seksuele losbandigheid en politieke selfsugtigheid. Sommige van hierdie mense behou uit gewoonte nog 'n formele band met die kerk (as deel van die kultuur); ander stel nie eers meer in 'n skyn van godsdienstigheid belang nie.

Hulle dryfkrag is "vooruitgang", en "genot" is die doel van hulle lewe, al veroorsaak die gejaag na al hierdie materiële voorspoed en geleenthede op die ou end dat daar min 
genot in die lewe oorbly. Om hierdie "post-Christelike mens" te bereik, stel nuwe eise aan die kerk. Dit is een van die dimensies van die samelewing wat deeglike aandag in die vorming van toekomstige leraars moet geniet. Die vraag kan gevra word of die gewone gereformeerde teologiese opleiding hiermee rekening hou. Het die deursnee teologiese student ' $n$ aanvoeling vir hierdie nuwe samelewing, of word hy/sy maar net voorberei vir werk onder mense wat nog met die Kerk tevrede is?

\section{Swak kerklike bediening}

In die tweede plek is baie lidmate naamchristene weens swak kerklike bediening. Talle (miljoene) mense het as gevolg van historiese prosesse deel van die kerklike gemeenskap geword, maar was nooit of lanklaas behoorlik kerklik betrokke.

- Verskeie swart stamme het in die vorige eeu reeds 'n bepaalde kerk as nie-amptelike stamgodsdiens aanvaar. Reeds destyds, maar ook later, is daar nooit daarin geslaag om al die stamlede tot persoonlike geloof in Christus te bring nie. Hierdie nominaliteit word nou oorgedra van geslag tot geslag.

- Op die plase van die "blanke" platteland was daar kerklik gesproke k!aarblyklik beter dae. Die uitgestrekte gebiede is vroeër vanaf die dorpe bedien met 'n uitgebreide reisende bediening. Verspreide buiteposte het 'n oppervlakkige verband van die plaasbevolking met veral die sending van die Afrikaanse Kerke moontlik gemaak. Algaande het die kerklike werk egter prakties tot die dorpe beperk geraak. Die armoede en tekort aan genoegsaam bekostigbare werkkragte het die kommunikasielyn met die plaasmense baie dun gemaak.

- 'n Derde voorbeeld wat genoem kan word (daar is meer), is die nuwe saamirekke wat in die tuislande, maar veral op die buitewyke van die stede ontstaan het. Ongelukkig was die gevestigde Kerke se strukture reeds deur die vorige vestigingspatroon gevorm en kon hulle nie tred hou met hierdie bevolkingverskuiwings nie. Op die Kaapse vlakte, waar die Kleurlinge op groot skaal hervestig is, het dit inderdaad gebeur dat die kerk oor die algemeen heelwat veld verloor het. Dieselfde gebeur nou met die groot nuwe stede van die swartes, want daar is net nie die infrastruktuur en mannekrag om die nuwe werk hier te vestig nie.

- In werklikheid moet elke nuwc geslag opnuut gekersten word. Die jeug van vandag het in vele opsigte vyande van die verlede geword, en die kerk behoort ook tot die 
ou bedeling. 'n Groot deel van die jeug neem nog deel, katkiseer en word lidmate. Baie van hulle bly egter volledig vreemdelinge. Die enkele produkte van ons teologiese skole wat die jeug kan bereik, doen dit gewoonlik ten koste van die ouer geslag, en soms skynbaar selfs ten koste van die evangelie.

Jit hoef amper nie uitgespel te word watter eise hierdie nuwe situasies aan die redieningstrukture en bedieningsbenadering stel nie. Ongelukkig word werklik min ran hierdie uitdagings sigbaar as na die geykte vorm van teologiese opleiding gekyk vord. Hoeveel van die kandidate vandag stel belang in die risiko, of is in staat om op lie plase of in die hervestigingsgebiede of informele saamtrekke die evangelie weer relevant te maak?

\section{3 'n Twyfelagtige Christendom}

'n Derde soort naamchristendom is wat ons kan beskryf as ' $n$ twyfelagtige Christendom. Die bedieningsvakuum wat orals in die situasies wat hierbo beskryf is ontstaan het, is op groot skaal gevul deur 'n verskeidenheid onafhanklike Kerke. Sommige van hulle is heel ortodoks in hulle geloofsoortuiginge, maar ander ongelukkig nie. In ieder geval word hulle almal gekenmerk deur die swak of gebrekkige opleiding van hulle leiers. Gevolglik heers daar soms grootskaalse verwarring oor die grondwaarhede van die Christelike geloof, in so 'n mate dat talle mense nie as Christene nie, maar as naamchristene bestempel sal moet word. Hoe kan die hoogs opgeleide gereformeerde predikante op hierdie leemte inspeel?

Hierdie toenemende naamchristendom in sy verskillende vorms mag dalk in die toekoms die grootste uitdaging vir die kerk in hierdie geweste blyk te wees. Wat baat dit as jy grootse planne en programme in die kerk het, maar die fondament waarop gebou word, is van sand? Die teologiese skole sal genoeg en die regte soort produkte moet lewer om aan hierdie taak te werk. Die teologiese skole sal ook leiding moet neem in die soeke na die soort strukture wat antwoorde op hierdie probleme kan bied. Die studente sal ook moet voorberei word op 'n minder bekende, uitdagende en selfs riskante bediening.

\section{DIE GROEIENDE ARMOEDE IN SUIDER-AFRIKA}

Ons het reeds in die verbygaan daarop gewys dat die armoede van 'n groot deel van die bevolking dit noodsaak dat die bedieningstrukture, en ook die opleiding van bedie- 
naars, grondig herdink moet word, want dit is te duur en laat die kerk in onoorkomelike probleme beland.

Die feit van armoede skep egter ook in 'n ander meer fundamentele opsig ' $n$ uitdaging aan die kerk. Ons moet dit aan die bevrydingsteoloë toegee wanneer hulle ons daaraan herinner dat die God van die Bybel steeds besondere sorg vir die armes en ander kwesbare persone vra. Dit is nie alleen in die Sinaïtiese wet uitgespel nie, maar die grootste profete van die Ou Testament het telkens die koning en die volk daaraan herinner. ' $n$ Veragting van hierdie eis het grootliks tot die volk van God se ondergang gelei. Jesus self het baie duidelik sy bediening op die armes en uitgeworpenes ingestel. Die kerk van Jesus Christus mag nie anders ingestel wees nie.

En tog het ons gereformeerde Kerke - swart en wit - ons nog nooit bewustelik hierop ingestel nie. 'n Groot deel van die Afrikaner se energie het in die eerste helfte van die eeu daarin gegaan om self vooruit te gaan. In die proses is die ander nie alleen nie meegeneem nie, maar dikwels veronagsaam. Blanke Christene het nog nie regtig besef dat die swart Kerke ' $n$ uiters arm gemeenskap bedien nie, maar koester nog middelklasverwagtings van hierdie Kerke, en dring slegs daarop aan dat die mense geleer moet word om na behore hulle finansiële bydrae te lewer.

Ook die swart Kerke self het nog nie die stryd teen die armoede as 'n prioriteit begin sien nie. Ongelukkig is dic leiers se energie grootliks aangewend in die stryd om eie finansiēle oorlewing en vooruitgang. Gevolglik is die armoedekultuur nie alleen nog nie aangepak nie, maar in werklikheid verder bestendig.

Die tweede Carnegie-ondersoek (vgl. Wilson \& Ramphele, 1989) het aan die lig gebring dat bykans die helfte van die Suid-Afrikaanse bevolking onder die broodlyn leef bykans twee-derdes van die swartes, en $80 \%$ van die plattelandse swartes! Dit is nie iets wat maar net met 'n skouerophaal afgemaak kan word nie. Navorsing dui aan dat, hoewel daar heelwat verblydende tendense is, die getal "hopeloses" aan die onderste punt van die leer in absolute getalle sterk toeneem. Die kerk mag hom - in die beeld van Matteus 25 - in die geselskap van die "bokke" vind, omdat die nodige nie vir "hierdie geringstes" gedoen is nie.

Die kerk sal eenvoudig - meer as in die verlede - sy bediening moet instem op die armes (in die pregnante betekenis van die woord). "Die evangelie vir die armes" sal gepreek en geleef moet word. 'n Teologie sal daarvoor ontwikkel moet word, en 'n geslag leraars moet opgelei word wat die instelling, die benadering en die metodes het 
om daaraan aandag te gee. Hierdie teologie sal ook veel meer Bybelgetrou en evangelies moet wees as 'n blote napraat van clichés van die bevrydingsteologie - die ware, omvattende bevryding van die armes sal gesoek moet word.

\section{DIE GROEIENDE STEDE IN SUIDER-AFRIKA}

Verstedeliking is 'n wèreldwye en stokou verskynsel. Die mens is 'n sosiale wese, en het gevolglik vanaf die vroegste tye saamgetrek in kolonies. Ou stede - ruïnes van antieke stede - kom oor die hele wêreld voor. Die negentiende-eeuse industriële rewolusie in die Weste, en die nuwe wereld wat daaruit gespruit het, het egter veroorsaak dat mense op 'n nuwe manier na die stede aangetrek is waar die fabrieke en produksieprosesse hulle nodig gehad het.

In hierdie eeu het daar weer eens 'n belangrike element bygekom. Die bevolkingsgroei op die platteland (tesame met ander faktore) het dit gaandeweg onmoontlik gemaak dat al die miljoene op dieselfde manier as vroeër op die platteland 'n bestaan kon voer. Nou stoot die platteland sy oortollige mense van hom af weg - na die stede toe. Daarom is die mees oorweldigende verskyningsvorm van verstedeliking vandag in die sogenaamde Derde Wêreld te sien. Met al die miljoene ontredderde mense - opdrifsels van die oorstroomde platteland - wat na die stede stroom, weet die armer lande van Afrika, Asië en Latyns-Ameriks nie raad nie. Plakkerbuurte (slums, favelas of barrios genoem) word die kenmerk van die groeiende stede. Miljoene mense - tot twee-derdes van die bevolking van sommige stede - woon in hierdie onbeplande buurtes met hulle baie moeilike omstandighede.

Verstedeliking in Suider-Afrika deel hierdie dryfkragte en verskynsels, maar daar is ook nog enkele unieke faktore wat bykom. Ons kan twee noem: die voorkoms van gedwonge verskuiwings waardeur talle onnatuurlike saamtrekke in die tuislande (en daarbuite) ontstaan het en die wetlik bepaalde rassegeskeidenheid van ons stede. Ons weet dat die swart verstedeliking, veral as gevolg van die vroeëre maatreëls van "instromingsbeheer", eintlik nog maar in sy beginstadium is. In die volgende dekade word 'n stedelike groei van nog nagenoeg 10 miljoen swartmense verwag. Die informele verstedeliking wat ons tans byvoorbeeld rondom Durban, op die Kaapse vlakte en noord van Pretoria sien, is een aspek daarvan. Maar ook nuwe formele stede en uitbreidings aan bestaande stede gaan grootliks toeneem. Dit is ook noodwendig dat die rasgeskeie karakter van ons stede gaan plek maak vir 'n baie meer vloeibare situasie. 
Bloot uit beplanningsoogpunt stel die verstedeliking geweldige eise aan die kerk. Veral waar saamtrekke ontstaan waar vroeër net weivelde of mielielande was, is die kerk en sy bediening in die moeilikheid. Daar moet ' $n$ buigbaarheid en spontaneïteit in die bedieningstrukture en voorsiening van werkkragte kom ten einde hierdie soort uitdagings die hoof te kan bied.

Wat egter nie vergeet moet word nie, is dat verstedeliking nie net ' $n$ kwantitatiewe begrip - miljoene mense wat stede toe stroom - is nie, maar ook 'n kwalitatiewe begrip. Die stad verander mense. Daar is 'n gees in die stad wat met die wind gedra word tot ver in die uithoeke van die platteland. Verstedeliking is modernisasie, 'n nuwe uitkyk op die lewe, 'n nie-tradisonele siening. Alles waaraan ons gewoond was - of ons Christene is of heidene - word geskud en omver gewerp. Verstedeliking is ' $n$ aardbewing.

Is die kerk en sy teologiese opleiding al gereed hiervoor? Of is ons teologiese skole nog by uitstek (by wyse van spreke) plattelands - plekke waar die ou (reeds vergane) bedeling nog steeds as die geldende aanvaar word? Dit lyk soms asof die kerk met elke omwenteling wat oor die samelewing spoel, verder agter raak. Is dit nie weer besig om in die stedelike rewolusie te gebeur nie? Soos met elkeen van die ander uitdagings wat ons genoem het, het die vernuwing in teologiese opleiding twee dimensies: 'n nuwe mentaliteit en nuwe strukture. ' $n$ Wil, 'n visie moet by die jong predikante ingeskerp word sodat hulle gewillig sal wees om die nuwe "sendingveld" in te gaan. Maar daar moet ook gewerk word aan nuwe maniere om die bediening uit te voer.

\section{DIE GROEIENDE GEMEENSKAPLJKHEID IN SUIDER-AFRIKA}

Ons het in die verbygaan melding gemaak daarvan dat die (gedwonge) rasgeskeidenheid in ons stede nie veel hoop het om die jaar 2000 te haal nie. En dit is maar simbolies van 'n werklikheid wat in Suid-Afrika in die oë gekyk sal moet word: SuidAfrika is ' $n$ veelrassige land wat in die toekoms al meer tot 'n gemeenskaplikheid en interaksie gaan groei4. Apartheid is dood, al sal verskeidenheid (hopelik) nie opgehef word nie.

Dit gaan die konteks van teologiese opleiding ingrypend verander. Tot nou toe kon (in ieder geval in gereformeerde kringe) feitlik probleemloos uitgegaan word van 'n tweër-

\footnotetext{
1 Daar is natuurlik mense wat ten alle koste hierteen weerstand gaan bied. Alle argumente volkekundig sosjologies, opvoedkundig ook godsdienstig - gaan opgewerp word teen hierdie ontwikkeling, maar waarskynlik met dieselfde gebrek aan sukses waarmee teen die swart versledeliking gestry is.
} 
lei konteks in Suid-Afrika: 'n blanke en 'n nie-blanke wêreld. Daar is rustig afsonderlike teologiese skole vir die blankes en vir die ander opgerig. Tog was daar in die praktyk nie twee afsonderlike kontekstuele opleidings met elk sy eie teologiese stempel nie, maar twee afsonderlike opleidings met dieselfde soort (wit) teologie ${ }^{5}$. (Op dieselfde manier oorheers die swart konteks in ander kerklike kringe, al is daar gestrewe na 'n samegroeiing van die groepe.)

Sonder om te veel te vereenvoudig, kan dit aanvaar word dat die groeiende gemeenskaplikheid van die "nuwe Suid-Afrika" dit toenemend moeilik, en ongewens sal maak om die twee kontekste van mekaar geîsoleerd te probeer hou. Dit gaan nog meer as tans nodig word om die teologie te beoefen en predikante op te lei in 'n situasie van gemeenskaplikheid en interaksie. Altans, dit lyk na die eis van die tyd ${ }^{6}$. Teologies gesproke lyk dit asof dit die eenheid is wat beklemtoon moet word, sodat die verskeidenheid daarbinne sy verrykende rol sal kan speel, en nie andersom nie.

Ek kry die indruk dat hierdie vraagstuk reeds volledig op die agenda van die gereformeerde teologiese skole is. Die vraag is: hoe gaan dit met die oog op die toekoms hanteer word?

\section{BIBLIOGRAFIE}

GLASSER, A.F., HIEBERT, P.G., WAGNER, C.P. \& WINTER, R.D. 1976. Crucial dimensions in world evangelization. Pasadena : William Carey Library.

HASTINGS, A. 1967. Church and mission in modern Africa. New York : Fordham University Press.

KRITZINGER, J.J. 1979. 'n Missionêre bediening. Op weg na strukture vir 'n jong kerk. Pretoria : NGKB.

KRITZINGER, J J. 1988. Die onvoltooide sendingtaak in Suid-Afrika. Pretoria : ISWEN

MöLLER, HJ. 1974. Die kerk onder die stedelike Bantoe. (Decl IV). Pretoria : RGN.

ODENDAAL, A.A. 1980. Tendense in die teologiese opleiding van swart leraars (1945-1977). NGTT 21(3):241-252, Junie.

PRETORIUS, H.L. 1980a. Die wit dosent voor 'n swart klas (1) - 'n agtergrondsverkenning. NGTT 21(3):253-266, Junic.

${ }^{5}$ Die ongemaklike feit is dat die teologiese skole van die Gereformeerde, Hervormde en Nederduitse-Gereformeerde Kerke waar (hoofsaaklik) swartmense opgelei word tol vandag toe (met enkele uitsonderings) beman word deur blanke dosente. Ook die swart dosente is op hulle beurt maar weer produkte van die wit teologiese wêrcld. Vergelyk die indringende artikcls van Pretorius oor hierdie problematiek (1980(a) en 1980(b)).

${ }^{6}$ Natuurlik sal ook hier steeds 'n aandrang op die teendeel wees, om juis te bevestig wat uniek was aan die verskillende gemeenskappe. Daar is natuurlik ook goeie argumente wat daarvoor aangebied kan word. 
PRETORIUS, H.L. 1980b. Die wit dosent voor 'n swart klas (2) - analise van 'n model. NGGTT 21(4):313-328, September.

PRETORIUS, H.L. 1986. Relevante teologiese opleiding in belang van 'n missionêre kerk. (In Du Preez, J., Pauw, C.M. \& Robinson, P J. reds. Sendingenende. 'n Feesbundel vir WJ.van der Merwe. Bloemfontein : NG Sendinguilgewers. p. 238-247.)

VAN DER WALT, BJ. 1988. Relevant Christian theological education for Africa. Ongepubliseerde referaat te Potchefstroom by 'n konferensie van die Interkerklike Komitee vir Nywerheidsbediening.

VAN EEDEN, IJ. \& SMUTS, M. reds. 1986. Kerkspiečl II. Pretoria : NGKB.

WILSON, F. \& RAMPHELE, M. 1989. Uprooting poverty. The South African challenge. Cape Town : David Philip. 